Competition, Strategic Delegation and Delay in Technology Adoption

A. Mahathi and RupayanPal

Indira Gandhi Institute of Development Research, Mumbai August 2013

http://www.igidr.ac.in/pdf/publication/WP-2013-016.pdf 


\title{
Competition, Strategic Delegation and Delay in Technology Adoption
}

\author{
A. Mahathi and RupayanPal \\ Indira Gandhi Institute of Development Research (IGIDR) \\ General Arun Kumar Vaidya Marg \\ Goregaon (E), Mumbai- 400065, INDIA \\ Email (corresponding author): $\quad$ rupayan@igidr.ac.in
}

\begin{abstract}
This paper examines how strategic managerial delegation affects firms' timing of adoption of a new technology under different modes of product market competition. It demonstrates that delegation has differential impacts on adoption dates under Cournot and Bertrand competition. Delegation with 'own-performance' based incentive schemes always leads to early adoption in markets with Bertrand competition compared to that under no-delegation, but not necessarily so in markets with Cournot competition. It also shows that the ranking of Cournot and Bertrand equilibria in terms of delay in adoption depends on the type of managerial incentive schemes. Adoption occurs earlier (later) in markets with Cournot competition than in markets with Bertrand competition, if product differentiation is high (low), regardless of whether there is no-delegation or delegation with 'own-performance' based incentive schemes. In contrast, under strategic delegation with 'relative-performance' based incentive schemes, adoption dates do not differ across markets with different modes of competition.
\end{abstract}

Keywords: Technology adoption, Strategic delegation, Own-performance, Relative-performance, Cournot, Bertrand

JEL Code: L13, L22, O31, O32, 033

Acknowledgements: 


\title{
Competition, Strategic Delegation and Delay in Technology Adoption A. Mahathi ${ }^{\dagger}$ and RupayanPal ${ }^{\dagger}$
}

Indira Gandhi Institute of Development Research (IGIDR), India ${ }^{1}$

\begin{abstract}
This paper examines how strategic managerial delegation affects firms' timing of adoption of a new technology under different modes of product market competition. It demonstrates that delegation has differential impacts on adoption dates under Cournot and Bertrand competition. Delegation with 'own-performance' based incentive schemes always leads to early adoption in markets with Bertrand competition compared to that under no-delegation, but not necessarily so in markets with Cournot competition. It also shows that the ranking of Cournot and Bertrand equilibria in terms of delay in adoption depends on the type of managerial incentive schemes. Adoption occurs earlier (later) in markets with Cournot competition than in markets with Bertrand competition, if product differentiation is high (low), regardless of whether there is no-delegation or delegation with 'own-performance' based incentive schemes. In contrast, under strategic delegation with 'relative-performance' based incentive schemes, adoption dates do not differ across markets with different modes of competition.
\end{abstract}

Key words: Technology adoption, Strategic delegation, Own-performance, Relative-performance, Cournot, Bertrand

JEL classification: L13, L22, O31, O32, O33

\section{Introduction}

How does strategic managerial delegation in oligopoly affect the timings of technology adoption? Does that depend on the mode of product market competition? Is there any role of the type of incentive schemes offered to managers in the case of delegation? This paper attempts to answer these questions.

It is widely observed that firms often do not adopt a technology as soon as it becomes available. Instead, firms delay to adopt new technology and the length of such delay varies across industries

\footnotetext{
${ }^{1}$ Corresponding Address: Rupayan Pal, Indira Gandhi Institute of Development Research (IGIDR), Film City Road, Santosh Nagar, Goregaon (East), Mumbai 400065, India.

E-mail: Trupayan@igidr.ac.in, rupayanpal@gmail.com; fmahathi@igidr.ac.in

Telephone: +91-22-28416545, Fax: +91-22-28402752.
} 
as well as across firms in the same industry. Several studies have attempted to explain this phenomenon. $^{2}$ This stream of literature offers useful insights to understand the implications of various factors, such as uncertainty regarding the value of newly available technology (Jensen, 1982; Balcer and Lippman, 1984; Bhattacharya et al., 1986; Jensen, 2004), strategic interaction between sellers and buyers of technology and their market powers (Stoneman and Ireland, 1983; Ireland and Stoneman, 1986; Rivas 2010), pre-commitment by firms in oligopoly and decreasing cost of technology adoption over time (Reinganum, 1981a\& 1981b; Quirmbach, 1986), preemption incentive in oligopoly (Fudenberg and Tirole,1985; Riordan and Salant, 1994), informational externality (Chamley and Gale, 1994), network externality (Choi and Thum, 1998), technological breakthrough versus improvement (Doraszelski, 2004), mode of product market competition (Milliou and Petrakis, 2011), etc., to firm's optimal timing of technology adoption. However, to the best of our knowledge existing models of technology diffusion do not allow for the possibility of delegation of authority within firms, although it is a common phenomenon in modern firms that face imperfect competition.

It is well argued that in oligopoly managerial delegation within firms, which arises due to strategic reasons, has significant effect on firms' profits. Moreover, the sign and magnitude of the effect of strategic managerial delegation on profits depend on the mode of product market competition, price or quantity, and on the type of incentive schemes considered (Vickers, 1985; Fershtman and Judd, 1987; Miller and Pazgal, 2001). ${ }^{3}$ It implies that managerial delegation is likely to affect firms' incentives to adopt new technology. Therefore, it seems to be important to examine the implications of managerial delegation on timings of technology adoption, by considering different types of incentive schemes, under alternative modes of product market competition. In order to address these issues, in this paper we extend the analysis of Milliou and Petrakis (2011) to allow for strategic managerial delegation.

We consider that there is a differentiated products duopoly with symmetric firms that initially employ the same production technology. Each of the two owners of firms contemplates on adopting a newly available cost-reducing technology, which has decreasing adoption-cost over time, and decides the timing of technology adoption. However, in each firm the task to set price or

\footnotetext{
2 See Hoppe (2002) for an extensive survey of the literature on timing of adoption of new technologies.

${ }^{3}$ We note here that, other than due to strategic reasons, managerial delegation may arise due to existence of asymmetric information between an owner and her manager and their conflicting objectives as well (Holmstrom, 1977; Harris and Raviv, 1979; Bolton and Dewatripont, 2004). However, to keep the analysis tractable we consider a complete information scenario and focus on strategic managerial delegation in this paper.
} 
quantity, depending on the exogenously determined mode of product market competition, is delegated by the owner to her manager in each date. Note that, if a firm adopts the new technology sooner than its rival firm, it enjoys competitive advantage as long as its rival does not adopt the new technology. On the other hand, if a firm adopts the new technology after its rival, it incurs lower cost of adoption compared to that of its rival. We explore this trade-off in different scenarios by considering that each firm can pre-commit to its adoption date.

First, by considering 'own-performance' based managerial incentive schemes in the case of strategic managerial delegation as in Fershtman and Judd (1987), we demonstrate that impact of delegation on diffusion of new technology in markets with Cournot competition is different from that in markets with Bertrand competition. Each firm adopts the new technology sooner in markets with Bertrand competition under delegation with 'own-performance' based managerial incentive schemes compared to that under no delegation, regardless of the degree of product differentiation. However, in markets with Cournot competition delays in technology adoption need not necessarily be lower under delegation with 'own-performance' based managerial incentive schemes compared to that under no delegation.

Comparing the equilibrium adoption dates under alternative modes of product market competition we find that, if products are sufficiently differentiated, the first firm adopts the technology sooner in markets with Cournot competition than in markets with Bertrand competition; and the opposite is true in the case of closely substitute products. In contrast, the second firm adopts the technology sooner in markets with Cournot competition compared to that in markets with Bertrand competition, irrespective of the degree of product differentiation. These results hold true both under delegation with 'own-performance' based managerial incentive schemes and under no delegation. Therefore, Milliou and Petrakis (2011)'s ranking of Cournot and Bertrand equilibria in terms of delay in technology adoption, in the case of pre-commitment game, does not alter due to introduction of strategic managerial delegation with 'own-performance' based managerial incentive schemes.

Next, we show that the equilibrium dates of technology adoption do not depend on the mode of product market competition, under strategic managerial delegation with 'relative-performance' based incentive schemes as considered in Miller and Pazgal (2001). It implies that (a) implication of strategic managerial delegation on diffusion of new technology crucially depends on the type of managerial incentive scheme considered and (b) effects of the mode of product market 
competition and other market features on dates of technology adoption are sensitive to firms' internal organization and incentive structures.

The rest of the paper is organised as follows. The next section presents the basic setup of the model. Section 3 examines the effects of strategic managerial delegation with 'own-performance' based incentive schemes on timings of technology adoption under Cournot and Bertrand competition. Section 4 considers the case of strategic managerial delegation with 'relativeperformance' based incentive schemes. Section 5 concludes.

\section{The Model}

We consider that there are two firms producing differentiated products. Initially, each firm incurs the constant marginal cost of production $c$. The inverse demand function for good $i$ is given by $p_{i}=a-q_{i}-\beta q_{j} ; i, j=1,2 ; i \neq j$,

where the parameter $\beta \in(0,1)$ measures the degree of product differentiation and $a$ is the demand intercept. Higher value of $\beta$ indicates lower (greater) degree of product differentiation

(substitution). For simplicity, we assume that $\frac{a-c}{d}>\frac{\beta}{2-\beta-\beta^{2}}$, which ensures that the equilibrium output of each firm is always positive.

Following Milliou and Petrakis (2011), we assume that time is continuous and technology can be adopted instantaneously at any point in time. The new technology becomes available at time $t=$ 0 . If a firm adopts the new technology, the marginal cost of production of that firm decreases from $c$ to $(c-d)$. That is, if firm $i(=1,2)$ adopts the technology at time $T_{i}$, its marginal cost is as follows.

$$
c_{i}=\left\{\begin{array}{c}
c, \text { if } T<T_{i} \\
c-d, \text { if } T \geq T_{i}
\end{array}\right.
$$

The cost of adopting the new technology at time $t$ is $k(t)$. Thus, $k(t) e^{r t}$ is the current cost of adopting the new technology at time $t$, where $r \in(0,1)$ is the rate of interest. We also assume that over time the current cost of adopting the new technology decreases at a decreasing rate: $\frac{d\left[k(t) e^{r t}\right]}{d t}<0$ and $\frac{d^{2}\left[k(t) e^{r t}\right]}{d t^{2}}>0$.

We consider that the owner of a firm may delegate the authority to decide the magnitude of the strategic variable, quantity or price, depending on the exogenously determined mode of product market competition to her manager by offering the manager an appropriately designed incentive 
scheme. However, owner of each firm retains the authority to decide the timing of technology adoption.

Following the literature on strategic managerial delegation, we assume that the managers are risk neutral and managerial market is perfectly competitive. In order to examine the role of the nature of delegation contracts, we consider two types of incentive schemes, separately. First, we consider that the owner of each firm offers the incentive scheme of following form.

$$
O_{i}=\alpha_{i} \pi_{i}+\left(1-\alpha_{i}\right) S_{i}, \quad i=1,2,
$$

where $\pi_{i}=p_{i} q_{i}-c_{i} q_{i}$ denotes the profit of firm $i$ (without deducting the fixed of technology adoption, if any), $S_{i}=p_{i} q_{i}$ denotes the sales revenue of firm $i$ and $\alpha_{i}$ is the incentive parameter chosen by the owner of firm $i$, as in Fershtman and Judd (1987). That is, the incentive scheme is a linear combination of own profit and own sales revenue. We refer this incentive scheme as 'ownperformance' based incentive scheme. Next, we consider that the owners offer 'relativeperformance' based incentive schemes of the following form, as in Miller and Pazgal (2001).

$$
O_{i}=\pi_{i}+\lambda_{i} \pi_{j}, \quad i, j=1,2, \quad i \neq j,
$$

where $\pi_{i}$ and $\pi_{j}$ are the profits of firm $i$ and firm $j$, respectively, and $\lambda_{i}$ is the incentive parameter chosen by the owner of firm $i$.

\section{Own-performance based delegation contracts}

Let us first consider that each owner offers 'own-performance' based incentive scheme, as in (1), to her manager. As mentioned before, the manager of each firm sets its quantity or price, depending on the exogenously determined mode of product market competition, in each date, while the decision of timing of technology adoption resides with the owner. That is, we assume that at time $t=0$ the owner of firm $i$ can credibly pre-commit its date of technology adoption $T_{i}, i=1,2$. The stages of the game involved are as follows.

Stage 1: At time $\mathrm{t}=0$, the owners independently and simultaneously decide the timing of technology adoption, $T_{i}$, so that the present values of their respective profits are maximized. The owners make this decision by considering their profits over an infinite time horizon.

Stage 2: At each point of time $t$, each firm's owner independently and simultaneously designs the incentive scheme $\left(O_{i}\right)$ by choosing the incentive parameter $\left(\alpha_{i}\right)$, so that her profit at that time $\pi_{i}\left(\alpha_{i}, \alpha_{j}\right) \quad(i, j=1,2 ; i \neq j)$ is maximized, for her manager and delegates the task to set the price or quantity depending on the mode of product market competition. 
Stage 3: The managers engage themselves in Cournot or Bertrand competition in the product market at each point of time $t$, where the objective function of the manager of firm $i$ at time $t$ is $O_{i}=\alpha_{i} \pi_{i}-\left(1-\alpha_{i}\right) S_{i}, \quad i, j=1,2 ; i \neq j$.

We solve this game by standard backward induction method, by considering Cournot competition and Bertrand competition separately in stage 3.

Let us denote the stage 2 equilibrium profit of firm $i(=1,2)$, when the product market competition is of $H$ type, by $\pi_{i}^{H}\left(c_{i}, c_{j}\right)$; where $H \in\{C, C D, B, B D\}$ and $C, C D, B, B D$ represent Cournot competition without delegation, Cournot competition with delegation, Bertrand competition without delegation and Bertrand competition with delegation, respectively.

Without any loss of generality we consider that, if firms adopt the new technology sequentially, the owner of firm 1 commits to adopts at an earlier date than the owner of firm 2: $T_{1}<T_{2}$. Therefore, we can write the stage 1 problems of firm 1 and firm 2, respectively, as in (3) and (4).

$$
\begin{aligned}
& \underset{T_{1}}{\operatorname{Max}} \int_{0}^{T_{1}} \pi_{1}^{H}(c, c) e^{-r t} d t+\int_{T_{1}}^{T_{2}} \pi_{1}^{H}(c-d, c) e^{-r t} d t+\int_{T_{2}}^{\infty} \pi_{1}^{H}(c-d, c-d) e^{-r t} d t-k\left(T_{1}\right)(3) \\
& \underset{T_{2}}{\operatorname{Max}} \int_{0}^{T_{1}} \pi_{2}^{H}(c, c) e^{-r t} d t+\int_{T_{1}}^{T_{2}} \pi_{2}^{H}(c, c-d) e^{-r t} d t+\int_{T_{2}}^{\infty} \pi_{2}^{H}(c-d, c-d) e^{-r t} d t-k\left(T_{2}\right)(4)
\end{aligned}
$$

From the first order conditions of (3) and (4), we get

$$
\begin{aligned}
I_{1}^{H} & =\pi_{1}^{H}(c-d, c)-\pi_{1}^{H}(c, c)=-k^{\prime}\left(T_{1}\right) e^{r T_{1}} \\
\text { and } I_{2}^{H} & =\pi_{2}^{H}(c-d, c-d)-\pi_{2}^{H}(c, c-d)=-k^{\prime}\left(T_{2}\right) e^{r T_{2}},
\end{aligned}
$$

respectively. Note that $I_{1}^{H}$ and $I_{2}^{H}$ are the marginal gains, i.e., incremental profits, from technology adoption of firm 1 and firm 2, respectively, when the product market competition is of type $H$. (5) and (6) implies that the optimal timing of technology adoption for firm $i(=1,2)$ is such that its marginal gain $\left(I_{i}^{H}\right)$ from adoption is equal to its cost of waiting $\left(-k^{\prime}\left(T_{i}\right) e^{r T_{i}}\right)$. Since the cost of technology decreases at a decreasing rate over time, greater incremental profit would lead to faster adoption of new technology. In other words, if the incremental profit of firm $i$ under competition type $H^{\prime}$ is greater than that under competition type $H^{\prime \prime}$, it is optimal for firm $i$ to adopt the technology sooner under $H^{\prime}$ than that under $H^{\prime \prime}$ :

$I_{i}^{H^{\prime}}>I_{i}^{H^{\prime \prime}} \Leftrightarrow T_{i}^{H^{\prime}}<T_{i}^{H^{\prime \prime}}$; where $H^{\prime}, H^{\prime \prime} \in\{C, C D, B, B D\}, H^{\prime} \neq H^{\prime \prime}, \quad i=1,2$. 
Now, given the timings of technology adoption by the two competing firms, under Cournot competition with 'own-performance' based delegation contractsfirm $i$ 's equilibrium incentive parameter, output and profit are, respectively, as follows.

$$
\left.\begin{array}{c}
\alpha_{i}\left(c_{i}, c_{j}\right)=1-\frac{\beta^{2}\left[a\{4-\beta(2+\beta)\}-\left(4-\beta^{2}\right) c_{i}+2 \beta c_{j}\right]}{\left(16-12 \beta^{2}+4 \beta^{4}\right) c_{i}}=\alpha_{i}^{C D}\left(c_{i}, c_{j}\right)<1, \\
q_{i}\left(c_{i}, c_{j}\right)=\frac{a(2-\beta)-2 c_{i} \alpha_{i}^{C D}+\beta c_{j} \alpha_{j}^{C D}}{4-\beta^{2}}=q_{i}^{C D}\left(c_{i}, c_{j}\right), \text { and } \\
\pi_{i}\left(c_{i}, c_{j}\right)=q_{i}^{C D}\left[q_{i}^{C D}-\left(1-\alpha_{i}^{C D}\right) c_{i}\right]=\pi_{i}^{C D}\left(c_{i}, c_{j}\right) ; i, j=1,2 \text { and } i \neq j ;
\end{array}\right\}
$$

where the superscript ' $C D$ ' indicates Cournot equilibrium under 'own-performance' based delegation contracts. Needless to mention here that $\alpha_{i}\left(c_{i}, c_{j}\right)=1$ corresponds to the case of no delegation. Comparing the increamental profits of firm $i$ under Cournot competition with delegation $\left(I_{i}^{C D}\right)$ and without delegation $\left(I_{i}^{C}\right)$, we obtain the following proposition.

Proposition 1: In markets with Cournot competition, strategic managerial delegation with 'ownperformance' based incentive scheme leads to higher rates of technology adoption compared to that under no delegation, if products are sufficiently close substitutes. Otherwise, if products are not sufficiently close substitutes, whether strategic managerial delegation with 'ownperformance' based incentive scheme enhances or decreases the rate of technology adoption that depends on the magnitude of the marginal cost reducing effect of new technology.

Proof: See Appendix.

The intution behind this result are as follows. In the case of Cournot competition without delegation, technology adoption by a firm has two effects. First, it reduces the marginal cost of the adopting firm, which adversely affects the output of the rival firm and, thus, increases the adopting firm's profit. That is, there is astrategic effect of technology adoption on adopting firm's profit, which is positive under Cournot competition. It is easy to check that the strategic effect is weaker in the case of higher degree of product differentiation, since in that case interdependence between markets of good 1 and good 2 is lower. Second, technology adoption by a firm reduces the adopting firm's marginal cost, which has direct positive effect on output and, thus, on profit of the adopting firm. In other words, other than strategic effect, there is adirect effect of technology adoption on adopting firm's profit, which is also positive under Cournot competition. Now, since in the case of Cournot competition with delegation the equilibrium incentive parameters are less than one $\left(\alpha_{i}^{C D}\left(c_{i}, c_{j}\right)<1\right)$, each firm behaves more aggreesively in the product market, i.e., set 
higher quantities, and earns lower profitsin the case of managerial delegation compared to that in absence of delegation. Further, in the case of delegation output of a firm is less sensitive to its marginal cost compared to that in absence of delegation. Thus, thepositive direct effect of technology adoption on adopting firm's profit reduces due to delegation. However, due to delegation, the technology adopting firm acquires greater market share than the non-adopting firm, which strengthens the positive strategic effect. Also, note that the optimal incentive parameter is lower in the case of higher degree of product substitutability ${ }^{4}$ and the extent of increase in market share of the adopting firm due to delegation is higher, if the new technology is more effective (i.e., if $d$ is larger). Therefore, the positive strategic effect of technology adoption on adopting firm's profit is stronger under delegation, if the degree of product substitutability is higher and/or new technology is more effective. As a result, if products are sufficiently close substitutes or the new technology brings about a large reduction in marginal cost, increase in strategic effect due to delegation over compensates the decrease in direct effect due to delegation. Thus, in the case of Cournot competition the first firm adopts the technology sooner under delegation compared to that under no delegation, if products are close substitutes or reduction in marginal cost due to technology adoption is sufficiently large. Following the same logic, the second firm also adopts the technology sooner (latter) under delegation than that under no delegation, if products are sufficiently close substitutes (differentiated). Otherwise, if products are neither sufficiently close substitutes nor sufficiently differentiated, effect of managerial delegation on the timing of adoption by the second firm depends on the effectiveness of new technology.

Now, we turn to examine the implications of 'own-performance' based incentive schemes on rates of technology adoption under Bertrand competition. In this case, the equilibrium incentive parameter, price and profit of firm $i$ are, respectively, as follows.

$$
\left.\begin{array}{c}
\alpha_{i}\left(c_{i}, c_{j}\right)=1+\frac{\beta^{2}\left[a(1-\beta)\{4+\beta(2-\beta)\}-\left(4-3 \beta^{2}\right) c_{i}+\beta\left(2-\beta^{2}\right) c_{j}\right]}{\left(16-12 \beta^{2}+\beta^{4}\right) c_{i}}=\alpha_{i}^{B D}\left(c_{i}, c_{j}\right)>1, \\
p_{i}\left(c_{i}, c_{j}\right)=\frac{a\left(2-\beta-\beta^{2}\right)+2 c_{i} \alpha_{i}^{B D}-\beta c_{j} \alpha_{j}^{B D}}{4-\beta^{2}}=p_{i}^{B D}\left(c_{i}, c_{j}\right), \text { and } \\
\pi_{i}\left(c_{i}, c_{j}\right)=\frac{\left(p_{i}^{B D}-c_{i}\right)\left(p_{i}^{B D}-\alpha_{i}^{B D} c_{i}\right)}{1-\beta^{2}}=\pi_{i}^{B D}\left(c_{i}, c_{j}\right), j=1,2 \text { and } i \neq j
\end{array}\right\}
$$

where the superscript ' $B D$ ' indicates Bertrand equilibrium under 'own-performance' based delegation contracts. Needless to mention here that we get equilibrium prices and profits under Bertrand competition without delegation by substituting $\alpha_{i}^{B D}\left(c_{i}, c_{j}\right)=1$ in the above expressions

$4 \frac{\delta \alpha_{i}^{C D}}{\delta \beta}=-\frac{2 \beta\left[8 c_{i}\left(8+4 \beta^{2}-\beta^{4}\right)+c_{j} \beta\left(48-12 \beta^{2}-\beta^{4}\right)+a(4+\beta)\{4-\beta(2+\beta)\}^{2}\right]}{c_{i}\left(16-12 \beta^{2}+\beta^{4}\right)^{2}}<0$ 
for $p_{i}\left(c_{i}, c_{j}\right)$ and $\pi_{i}\left(c_{i}, c_{j}\right)$. Comparing the increamental profits of firm $i$ under Bertrand competition with delegation $\left(I_{i}^{B D}\right)$ and without delegation $\left(I_{i}^{B}\right)$, we obtain Proposition 2.

Proposition 2: In markets with Bertrand competition, the equilibrium rates of technology adoption by firms, under strategic managerial delegation with 'own-performance' based incentive scheme, are higher compared to that under no delegation.

Proof: See Appendix.

The underlying mechanism behind Proposition 3 is as follows. Note that in the case of Bertrand competition without delegation, technology adoption by a firm leads to reduction of its rival firm's price, since prices are strategic complements. And, reduction in one firm's price adversely affects the other firm's profit. Therefore, strategic effect of technology adoption on adopting firm's profit is negative in the case of Bertrand competition, unlike as in the case of Cournot competition. On the other hand, as in the case of Cournot competition, a firm's marginal cost reduces due to technology adoption, which leads to higher output and profit of the adopting firm under Bertrand competition as well. Thus, direct effect of technology adoption on adopting firm's profit is positive irrespective of the mode of product market competition. Direct effect always dominates strategic effect of technology adoption in the case of Bertrand competition without delegation. So, firms have incentives to adopt technology under Bertrand competition without delegation.

Now, in the case of 'own-performance based' managerial delegation under Bertrand competition, managers are penalized for sales maximization, since the equilibrium incentive parameters are greater than one: $\alpha_{i}^{B D}\left(c_{i}, c_{j}\right)>1$. It implies that the intensity of price undercutting is lower and the equilibrium prices are more sensitive to marginal costs under delegation compared to that under no delegation. Moreover, it can be easily checked that the lower the marginal cost of firm $i$, the higher the incentive parameter chosen by its owner: $\frac{\partial \alpha_{i}^{B D}}{\partial c_{i}}>0$. Thus, under delegation, a firm becomes even less aggressive price-setter, when it adopts the new technology. Therefore, in the case of Bertrand competition, delegation weakens the negative strategic effect and strengthens the positive direct effect of technology adoption on adopting firm's profit. So, in the case of Bertrand competition, firms adopt the new technology sooner under delegation than that under no delegation regardless of the degree of product differentiation. In fact, when products become 
closely related, the value of the incentive parameter increases further leading to a further fall in aggression and that in turn enhances incremental profits due to technology adoption.

Finally, we turn to examine whether the new technology is diffused faster in the case of Cournot competition or in the case of Bertrand competition. Is there any implication of 'own-performance' based delegation contracts on this comparison? Comparing the rates of technology adoption under alternative modes of product market competition, price and quantity, with and without delegation, we obtain the following.

Proposition 3: If the degree of product differentiation is low (high), Bertrand (Cournot) competition leads to faster adoption of new technology by the first firm regardless of whether there is no delegation or strategic managerial delegation with 'own-performance' based incentive scheme. However, the second firm adopts the technology faster under Cournot competition than that under Bertrand competition, both in the case of strategic managerial delegation with 'ownperformance' based incentive scheme and in the case of no delegation, regardless of the extent of product differentiation.

Proof: See Appendix.

Clearly, though strategic managerial delegation with 'own-performance' based incentive scheme has differential impacts on rates of technology adoption under alternative modes of competition, rankings of equilibrium adoption rates under Cournot and Bertrand competition do not alter due to such delegation contracts. It implies that the result of Milliou and Petrakis (2011) is robust to the introduction of 'own-performance' based managerial delegation contracts in firms. Note that, while both direct effect and strategic effect of technology adoption reinforces firms' incentives to adopt new technology under Cournot competition, these two effects work in opposite directions under Bertrand competition. However, since competition is more intense under Bertrand competition, positive direct effect of marginal cost reduction due to technology adoption on the first adopting firms' profit is much more prominent under Bertrand competition than that under Cournot competition, unless products are sufficiently differentiated. This is true regardless of whether there are 'own-performance' based managerial delegation contracts in firms or not, since such delegation strengthens (weakens) direct effect and weakens (strengthens) strategic effect of technology adoption under Bertrand (Cournot) competition. As a result, when products are close substitutes, the first firm always adopts the new technology sooner under Bertrand competition 
than under Cournot competition. The opposite is true, when products are sufficiently differentiated, since due to increase in degree of product differentiation direct effect of technology adoption reduces to a greater extent under Bertrand competition than under Cournot competition. For the second adopter, direct effect of technology adoption under Bertrand competition is lower than that under Cournot competition even when products are close substitutes. This is because, a reduction in second firm's marginal cost further intensifies price under-cutting under Bertrand competition, but under Cournot competition the first firm responds by setting a lower output. As a result, the gain in profit of the second firm due to technology adoption is higher under Cournot competition than that under Bertrand competition, irrespective of the degree of product differentiation and whether there are 'own-performance' based managerial delegation contracts in firms or not.

\section{Relative-performance based delegation contracts}

We now turn to examine whether rankings of rates of technology adoption under Cournot and Bertrand equilibria in the case of strategic managerial delegation are sensitive to the form of incentive schemes offered to managers. In order to do so, we consider an alternative scenario in which owners of each firm offer 'relative-performance' based incentive schemes as given by equation (2) to their respective managers, everything else remains the same as before. Solving the owners' problems in stage 2 after solving the problems of managers in stage 3 of the game, considering Bertrand and Cournot competition separately, we get the following stage 2 equilibrium outcomes.

$$
\left.\begin{array}{l}
\lambda_{i}^{B R D}\left(c_{i}, c_{j}\right)=\frac{\beta\left[a-c_{i}\right]}{a(2-\beta)+\beta c_{i}-2 c_{j}}>0, \\
\lambda_{i}^{C R D}\left(c_{i}, c_{j}\right)=-\frac{\beta\left[a(1-\beta)-c_{i}+\beta c_{j}\right]}{a\left(2-\beta-\beta^{2}\right)-2 c_{j}+\beta\left(c_{i}+\beta c_{j}\right)}<0, \\
\pi_{i}^{B R D}\left(c_{i}, c_{j}\right)=\pi_{i}^{C R D}\left(c_{i}, c_{j}\right)=\frac{\left\{a(2-\beta)-2 c_{i}+\beta c_{j}\right\}\left\{a\left(2-\beta-\beta^{2}\right)-\left(2-\beta^{2}\right) c_{i}+\beta c_{j}\right\}}{16\left(1-\beta^{2}\right)} ;
\end{array}\right\}
$$

where superscripts 'BRD' and 'CRD' denote, respectively, 'Bertrand competition with relativeperformance based delegation contracts' and 'Cournot competition with relative-performance based delegation contracts', $i, j=1,2$ and $i \neq j$.

From (10) it is evident that, for any given marginal costs $c_{i}$ and $c_{j}$, in the case of 'relativeperformance' based incentive schemes equilibrium profit of firm $i(=1,2)$ under Bertrand competition is the same as that under Cournot competition. In other words, Bertrand competition 
and Cournot competition yield the same level of profit in the case of strategic managerial delegation with 'relative-performance' based incentive schemes, as in Miller and Pazgal (2001). The reason is as follows. Cournot (Bertrand) equilibrium profits are lower (higher) in the case of strategic managerial delegation than that in the case of no delegation, regardless of whether owners offer 'own-performance' based incentive schemes or 'relative-performance' based incentive schemes to their respective managers in the case of delegations. However, unlike as in the case of 'own-performance' based incentive schemes, owners enjoy sufficient control over their managers in the case of 'relative-performance' based incentive schemes so that their equilibrium profits are invariant to modes of product market competition (Miller and Pazgal, 2001). Therefore, in the present scenario, we have the following.

$$
\begin{gathered}
I_{1}(B R D)=\pi_{1}^{B R D}(c-d, c)-\pi_{1}^{B R D}(c, c) \\
=\pi_{1}^{C R D}(c-d, c)-\pi_{1}^{C R D}(c, c) \\
=I_{1}(C R D)
\end{gathered}
$$

and

$$
\begin{gathered}
I_{2}(B R D)=\pi_{2}^{B R D}(c-d, c-d)-\pi_{2}^{B R D}(c, c-d) \\
=\pi_{2}^{C R D}(c-d, c-d)-\pi_{2}^{C R D}(c, c-d) \\
=I_{2}(C R D)
\end{gathered}
$$

Clearly, $(11) \Rightarrow T_{1}(B R D)=T_{1}(C R D)$ and $(12) \Rightarrow T_{2}(B R D)=T_{2}(C R D)$. Thus, firms' optimal timings of technology adoption under Bertrand competition are the same as that under Cournot competition, when owners offer 'relative-performance' based incentive schemes to their respective managers. Needless to mention here that such possibility does not arise in absence of strategic managerial delegation à la Milliou and Petrakis (2011) or in the case of strategic managerial delegation with 'own-performance' based delegation contracts. It implies that speed of diffusion of new technology need not necessarily vary with the mode of product market competition, it crucially depend on the type of internal incentive structure adopted by firms.

Proposition 4: In the case of strategic managerial delegation with 'relative-performance' based incentive schemes for managers, the equilibrium rates of technology adoption by firm 1 and firm 2 do not depend on whether there is Cournot competition or Bertrand competition in the product market. 


\section{Conclusion}

In this paper we have developed a model to examine possible effects of strategic managerial delegation in duopoly on diffusion of new technology under Cournot and Bertrand competition. We have shown that firms adopt the new technology sooner under 'own-performance' based delegation contracts compared to that in absence of managerial delegation in markets with Cournot competition, if products are sufficiently close substitutes. Otherwise, degree of product differentiation and magnitude of marginal cost reduction due adoption of new technology play crucial role in determining the effect of 'own-performance' based delegation contracts on timings of technology adoption. In contrast, in markets with Bertrand competition firms always adopt the new technology sooner under 'own-performance' based delegation contracts compared to that under no-delegation.

We have also shown that, though existence of 'own-performance' based delegation contracts in firms has differential impacts on timings of technology adoption under alternative modes of product market competition, the ranking of Cournot and Bertrand equilibria in terms of speed of technology diffusion under 'own-performance' based delegation contracts remain the same as that under no-delegation. Under each of these two scenarios, while the second firm adopts the new technology sooner in the case of Cournot competition than that in the case of Bertrand competition regardless of the degree of product differentiation, the first firm adopts the new technology sooner (later) in the case of Bertrand competition than that in the case of Cournot competition unless the degree of product differentiation is high (low). In contrast, under strategic managerial delegation with 'relative-performance' based incentive schemes, speed of diffusion of new technology does not depend on the mode of product market competition, price or quantity.

In this paper we have considered diffusion of productivity enhancing new technology and assumed that firms can pre-commit the timing of technology adoption. It seems to be interesting to extend the present analysis to the case of product quality enhancing new technology and to test the sensitivity of our results in alternative scenario in which owners cannot credibly pre-commit the timing of technology adoption. These are beyond the scope of the present paper. We leave these for future research. 


\section{Appendix}

\section{Proof of Proposition 1}

Using the expressions for equilibrium profits of firm 1 under Cournot competition with and without delegation from (8), we get the increamental profits of firm 1 due to technology adoption under Cournot competition with delegation and without delegation, respectively, as follows.

$I_{1}^{C}=\frac{(a-c)(2-\beta) 4 d+4 d^{2}}{\left(2-\beta^{2}\right)^{2}}$ and $I_{1}^{C D}=\frac{2 d\left(8-6 \beta^{2}+\beta^{4}\right)\left[2(a-c)\{4-\beta(2+\beta)\}+d\left(4-\beta^{2}\right)\right]}{\left(16-12 \beta^{2}+\beta^{4}\right)^{2}}$. Thus,

$I_{1}^{C D}-I_{1}^{C}=\frac{2 d \beta^{3}\left[d \beta\left(96-80 \beta^{2}+16 \beta^{4}-\beta^{6}\right)-2(a-c)(2-\beta)\{4-\beta(2+\beta)\}\left\{8-\beta\left(4+8 \beta-\beta^{2}-\beta^{3}\right)\right\}\right]}{\left[64-\beta^{2}\left(8-\beta^{2}\right)^{2}\right]^{2}}$.

Clearly, $I_{1}^{C D}-I_{1}^{C}>0$, if $d>\frac{2(a-c)(2-\beta)\{4-\beta(2+\beta)\}\left\{8-\beta\left(4+8 \beta-\beta^{2}-\beta^{3}\right)\right\}}{\beta\left(96-80 \beta^{2}+16 \beta^{4}-\beta^{6}\right)}=d_{0}$, which is negative (positive) if $0.8467 \leq \beta<1 \quad(0<\beta<0.8467)$. Therefore, if $0.8467 \leq \beta<1$, we have $I_{1}^{C D}-I_{1}^{C}>0$.

Now, by supposition, $d<\frac{(\mathrm{a}-\mathrm{c})\left(2-\beta-\beta^{2}\right)}{\beta}$, for equilibrium outputs to be positive. And, $\frac{(\mathrm{a}-\mathrm{c})\left(2-\beta-\beta^{2}\right)}{\beta}>d_{0} \forall \beta \in(0,1)$. It implies that, if $0<\beta<0.8467, I_{1}^{C D}-I_{1}^{C}>(<) 0$ when $d>(<) d_{0}$

Next, using the stage 3 equilibrium profits from (8), we obtain the incremenatal profits of firm 2 due to technology adoption under Cournot competition with delegation and without delegation are, respectively, as follows.

$$
\begin{aligned}
& I_{2}^{C}=\frac{(a-c)(2-\beta) 4 d+(1-\beta) 4 d^{2} \text { and }}{\left(4-\beta^{2}\right)^{2}} \\
& I_{2}^{C D}=\frac{2 d\left(4-\beta^{2}\right)\left(2-\beta^{2}\right)[2(a-c)\{4-\beta(2+\beta)\}+d\{4-\beta(4+\beta)\}]}{\left(16-12 \beta^{2}+\beta^{4}\right)^{2}} .
\end{aligned}
$$

Therefore,

$I_{2}^{C D}-I_{2}^{C}=\frac{2 d \beta^{3}\left[-d\left\{128-\beta\left(96+(2-\beta)^{2} \beta(4+\beta)\left(4-2 \beta-\beta^{2}\right)\right\}-2(a-c)(2-\beta)\{4-\beta(2+\beta)\}\left\{8-\beta\left(4+8 \beta-\beta^{2}-\beta^{3}\right)\right\}\right]\right.}{\left[64-\beta^{2}\left(8-\beta^{2}\right)^{2}\right]^{2}}$.

Thus, $I_{2}^{C D}-I_{2}^{C}>0 \Leftrightarrow d<\frac{-2(a-c)(2-\beta)\{4-\beta(2+\beta)\}\left\{8-\beta\left(4+8 \beta-\beta^{2}-\beta^{3}\right)\right\}}{128-\beta\left\{96+(2-\beta)^{2} \beta(4+\beta)\left(4-2 \beta-\beta^{2}\right)\right\}}=\hat{d}$, say. Upon inspection 
we find that (a) $\hat{d} \geq 0$, if $0.8467 \leq \beta<1$ and (b) $\hat{d} \geq \frac{(\mathrm{a}-\mathrm{c})\left(2-\beta-\beta^{2}\right)}{\beta}$, if $0.9613 \leq \beta<1$. It implies the following.

i) If $0.9613 \leq \beta<1, I_{2}^{C D}>I_{2}^{C}$.

ii) $\quad$ If $0.8467 \leq \beta<0.9613$ and $d<\hat{d}, I_{2}^{C D}>I_{2}^{C}$.

iii) If $0.8467 \leq \beta<0.9613$ and $\hat{d}<d<\frac{(\mathrm{a}-\mathrm{c})\left(2-\beta-\beta^{2}\right)}{\beta}, I_{2}^{C D}<I_{2}^{C}$.

iv) If $0<\beta<0.8467, I_{2}^{C D}<I_{2}^{C}$. [QED]

\section{Proof of Proposition 2}

From the equilibrium profits of firm 1 and firm 2 under Bertrand competition without delegation and with delegation, given by (9), we obtain the incremental profits of firms due to technology adoption as follows.

$$
\begin{aligned}
& I_{1}^{B}=\frac{d\left(2-\beta^{2}\right)\left[2 a\left(2-\beta-\beta^{2}\right)-2 c\left(2-\beta-\beta^{2}\right)+d\left(2-\beta^{2}\right)\right]}{\left(4-\beta^{2}\right)^{2}\left(1-\beta^{2}\right)}, \\
& I_{1}^{B D}=\frac{2 d\left(8-10 \beta^{2}+3 \beta^{4}\right)\left[2 a(1-\beta)\{4+(2-\beta) \beta\}-2 c(1-\beta)\{4+(2-\beta) \beta\}+d\left(4-3 \beta^{2}\right)\right]}{\left(1-\beta^{2}\right)\left(16-12 \beta^{2}+\beta^{4}\right)^{2}}, \\
& I_{2}^{B}=\frac{d\left(2-\beta^{2}\right)\left[2 a\left(2-\beta-\beta^{2}\right)-2 c\left(2-\beta-\beta^{2}\right)+d\{2-\beta(2+\beta)\}\right]}{\left(4-\beta^{2}\right)^{2}\left(1-\beta^{2}\right)} \text { and } \\
& I_{2}^{B D}=\frac{2 d\left(2-\beta^{2}\right)\left(4-3 \beta^{2}\right)\left[2 a(1-\beta)\{4+(2-\beta) \beta\}-2 c(1-\beta)\{4+(2-\beta) \beta\}+d(2-\beta)\left(2-\beta-2 \beta^{2}\right)\right]}{\left(1-\beta^{2}\right)\left(16-12 \beta^{2}+\beta^{4}\right)^{2}}
\end{aligned}
$$

where superscripts ' $B$ ' and ' $B D$ ' denote 'Bertrand competition without delegation' and 'Bertrand competition with delegation', respectively; subscripts ' 1 ' and ' 2 ' denote firm 1 and firm 2, respectively; and ' $I$ ' denotes incremental profit of a firm due to technology adoption.

Now,

$$
\begin{aligned}
& {\left[I_{1}^{B D}-I_{1}^{B}\right]} \\
& =\frac{2 d \beta^{3}\left(2-\beta^{2}\right)\left[2(a-c)(1-\beta)(2+\beta)\{4+(2-\beta) \beta\}\left\{8-4 \beta-(4-\beta) \beta^{2}\right\}-d \beta\left(32-32 \beta^{2}+8 \beta^{4}-\beta^{6}\right)\right]}{\left(1-\beta^{2}\right)\left[64-\beta^{2}\left(8-\beta^{2}\right)^{2}\right]^{2}}
\end{aligned}
$$

and $\left(I_{2}^{B D}-I_{2}^{B}\right)=\left(I_{1}^{B D}-I_{1}^{B}\right)+\frac{2 d^{2} \beta^{3}\left(2-\beta^{2}\right)\left(64-96 \beta^{2}+44 \beta^{4}-5 \beta^{6}\right)}{\left(1-\beta^{2}\right)\left[64-\beta^{2}\left(8-\beta^{2}\right)^{2}\right]^{2}}$.

Since $0<\beta<1,\left(32-32 \beta^{2}+8 \beta^{4}-\beta^{6}\right)>0$ and, thus,

$I_{1}^{B D}-I_{1}^{B}>0 \Rightarrow d<\frac{2(a-c)(1-\beta)(2+\beta)\{4+(2-\beta) \beta\}\left\{8-4 \beta-(4-\beta) \beta^{2}\right\}}{\beta\left(32-32 \beta^{2}+8 \beta^{4}-\beta^{6}\right)}=d_{1}$, say. 
We have $<\frac{(a-c)\left(2-\beta-\beta^{2}\right)}{\beta}$, by supposition. Now, $d_{1}-\frac{(a-c)\left(2-\beta-\beta^{2}\right)}{\beta}=\frac{2(a-c)(1-\beta)(2+\beta)\left[32-32 \beta^{2}+\beta^{4}\{4-(2-\beta) \beta\}\right]}{\beta\left(32-32 \beta^{2}+8 \beta^{4}-\beta^{6}\right)}>0$, since $0<\beta<1$. Therefore, we get $d_{1}>\frac{(a-c)\left(2-\beta-\beta^{2}\right)}{\beta} \forall \beta(0,1)$, which implies that $I_{1}^{B D}-I_{1}^{B}>0 \forall \beta(0,1)$.

Also, note that $\frac{2 d^{2} \beta^{3}\left(2-\beta^{2}\right)\left(64-96 \beta^{2}+44 \beta^{4}-5 \beta^{6}\right)}{\left(1-\beta^{2}\right)\left[64-\beta^{2}\left(8-\beta^{2}\right)^{2}\right]^{2}}>0$, since $0<\beta<1$. It implies that $I_{2}^{B D}-I_{2}^{B}>$ $0 \forall \beta(0,1)$, since $\left(I_{2}^{B D}-I_{2}^{B}\right)=\left(I_{1}^{B D}-I_{1}^{B}\right)+\frac{2 d^{2} \beta^{3}\left(2-\beta^{2}\right)\left(64-96 \beta^{2}+44 \beta^{4}-5 \beta^{6}\right)}{\left(1-\beta^{2}\right)\left[64-\beta^{2}\left(8-\beta^{2}\right)^{2}\right]^{2}}$ and $\left(I_{1}^{B D}-I_{1}^{B}\right)>$ 0.

[QED]

\section{Proof of Proposition 3}

Comparing the incremental benefits of the first firm under Cournot and Bertrand competition, we obtain the following.

$$
\begin{aligned}
& I_{1}^{C D}-I_{1}^{B D}=\frac{2 \beta^{5}\left(2-\beta^{2}\right) d\{2(1-\beta)(a-c)-\beta d\}}{\left(1-\beta^{2}\right)\left(16-12 \beta^{2}+\beta^{4}\right)^{2}}\left\{\begin{array}{c}
>0, \text { if } 0<\beta<\frac{2(a-c)}{2(a-c)+d} \\
<0, \text { if } \beta>\frac{2(a-c)}{2(a-c)+d} .
\end{array}\right. \\
& I_{1}^{C}-I_{1}^{B}=\frac{\left.d \beta^{3}[2(1-\beta)(a-c)-d \beta)\right]}{\left(1-\beta^{2}\right)\left(4-\beta^{2}\right)^{2}}\left\{\begin{array}{c}
>, \text { if } 0<\beta<\frac{2(a-c)}{2(a-c)+d} \\
<0, \text { if } \beta>\frac{2(a-c)}{2(a-c)+d}
\end{array}\right.
\end{aligned}
$$

Note that, $\frac{\beta}{2(1-\beta)}>\frac{\beta}{2-\beta-\beta^{2}} \forall \beta \in[0,1)$, and $\frac{a-c}{d}>\frac{\beta}{2-\beta-\beta^{2}}$ should be satisfied for equilibrium outputs to be positive. Thus, both $0<\beta<\frac{2(a-c)}{2(a-c)+d}$ and $\beta>\frac{2(a-c)}{2(a-c)+d}$ are plausible. Therefore, both $I_{1}^{C D}-I_{1}^{B D}$ and $I_{1}^{C}-I_{1}^{B}$ are positive if $0<\beta<\frac{2(a-c)}{2(a-c)+d}$. Otherwise, if $>\frac{2(a-c)}{2(a-c)+d}$, both $I_{1}^{C D}-I_{1}^{B D}$ and $I_{1}^{C}-I_{1}^{B}$ are negative.

Now, comparing the incremental benefits of the second firm under Cournot and Bertrand competition, we get

$$
\begin{aligned}
& I_{2}^{C}-I_{2}^{B}=\frac{d \beta^{3}\{2(1-\beta)(a-c)+d(2-\beta)\}}{\left(1-\beta^{2}\right)\left(4-\beta^{2}\right)^{2}}>0 \text { and } \\
& I_{2}^{C D}-I_{2}^{B D}=\frac{2 \beta^{5}\left(2-\beta^{2}\right) d\{2(1-\beta)(a-c)+d(2-\beta)\}}{\left(1-\beta^{2}\right)\left(16-12 \beta^{2}+\beta^{4}\right)^{2}}>0, \text { since } 0<\beta<1 .
\end{aligned}
$$




\section{References}

Balcer, Y. and Lippman, S. (1984). Technological expectations and adoption of improved technology. Journal of Economic Theory, 34(2):292-318.

Bhattacharya, S., Chatterjee, K. and Samuelson, L. (1986). Sequential research and the adoption of innovations. Oxford Economics Papers, 38(Suppl.):219-243.

Bolton, P. and Dewatripont, M. (2004). Contract Theory. MIT Press, Cambridge, MA.

Chamley, C. and Gale, D. (1994). Information revelation and strategic delay in a model of investment. Econometrica, 62(5):1065-1085.

Choi J. and Thum M. (1998). Market structure and the timing of technology adoption with network externalities. European Economic Review, 42(2): 225-244.

Doraszelski U. (2004). Innovations, improvements, and the optimal adoption of new technologies. Journal of Economic Dynamics and Control, 28(7):1461-1480.

Fershtman, C. and Judd, K. (1987). Equilibrium incentives in oligopoly. American Economic Review, 77(5):927-940.

Fudenberg, D. and Tirole.J. (1985). Pre-emption and rent equalization in the adoption of new technology. Review of Economic Studies, 52(3):383-401.

Harris, M. and Raviv, A. (1979). Optimal incentive contracts with imperfect information. Journal of Economic Theory, 20(2):231-259.

Holmstrom, B. (1977). On Incentives and Control in Organization. Ph.D. Dissertation,

Hoppe, H. (2002). The timing of new technology adoption: theoretical models and empirical evidence. Manchester School, 70(1):56-76.

Ireland, N. and Stoneman, P. (1986). Technological diffusion, expectations and welfare. Oxford Economic Papers, 38 (2):283-304. 
Jensen, R. (2004). Multiplant firms and innovation adoption and diffusion. Southern Economic Journal, 70(3): $661-671$.

Jensen, R. (1982). Adoption and diffusion of an innovation of uncertain profitability. Journal of Economic Theory, 27(1)182-192.

Miller, N. and Pazgal. H. (2001). The equivalence of price and quantity competition with delegation. RAND Journal of Economics. 32(2):284-301.

Milliou, C. and Petrakis, E. (2011). Timing of technology adoption and product market competition. International Journal of Industrial Organization, 29(5):513-523.

Quirmbach, H. C. (1986). The diffusion of new technology and the market for an innovation. RAND Journal of Economics, 17(1): 33-47.

Reinganum J. F. (1981a). On the diffusion of new technology: A game theoretic approach. Review of Economic Studies, 48 (3):395-405.

Reinganum, J.F. (1981b). Market structure and the diffusion of new technology. Bell Journal of Economics, 12(2): 618-624.

Riordan, M. H. and Salant, D. J. (1994). Pre-emptive adoptions of an emerging technology. Journal of Industrial Economics, 42(3), 247-261.

Rivas, J. (2010). The effects of the market structure on the adoption of evolving technologies. Journal of Economic Dynamics and Control, 34(12):2485-2493.

Stoneman, P. and Ireland, N.J. (1983). The role of supply factors in the diffusion of new process technology. Economic Journal, 93(369a):66-78.

Vickers, J. (1985). Delegation and the theory of the firm. Economic Journal, 95(380a):138-147. 